\title{
Ni-dispersed fullerenes: Hydrogen storage and desorption properties
}

\author{
Weon Ho Shin and Seong Ho Yang \\ Department of Materials Science and Engineering, Korea Advanced Institute of Science and Technology, \\ Kusung-dong 373-1, Yusung-gu, Daejon, Republic of Korea 305-701 \\ William A. Goddard III \\ Materials and Process Simulation Center, California Institute of Technology, Pasadena, California 91125 \\ Jeung Ku Kang ${ }^{\text {a) }}$ \\ Department of Materials Science and Engineering, Korea Advanced Institute of Science and Technology, \\ Kusung-dong 373-1, Yusung-gu, Daejon, Republic of Korea 305-701
}

(Received 10 October 2005; accepted 14 December 2005; published online 31 January 2006)

\begin{abstract}
Our study shows that the $\mathrm{H}_{2}$ storage media using $\mathrm{Ni}$-dispersed fullerenes could be viable alternatives to reversible hydrogen storage. It is demonstrated that a single Ni coated on the fullerene surface can store up to three $\mathrm{H}_{2}$ molecules. Consequently, at high $\mathrm{Ni}$ coverage, Ni-dispersed fullerenes are considered to be the novel hydrogen storage media capable of storing $\sim 6.8 \mathrm{wt} \% \mathrm{H}_{2}$, thus exceeding the Department of Energy target $(6.5 \mathrm{wt} \%)$ for automobile applications. Moreover, the $\mathrm{H}_{2}$ desorption activation barrier of $11.8 \mathrm{kcal} / \mathrm{mol} \mathrm{H}_{2}$ is ideal for many practical hydrogen storage applications. (C) 2006 American Institute of Physics. [DOI: 10.1063/1.2168775]
\end{abstract}

Hydrogen, which can be readily produced from renewable energy sources and mainly produces water as a byproduct, contains much larger chemical energy per mass (142 $\mathrm{MJ} \mathrm{kg}^{-1}$ ) (Ref. 1) than any hydrocarbon fuel. Consequently, it is considered as an ideal fuel to solve energy and environmental problems in the earth that result from using petroleum fuels. Many hydrogen storage methods have been proposed, such as carbon-fiber reinforced high-strength containers, ${ }^{2}$ liquid hydrogen, ${ }^{3}$ chemical hydrides, ${ }^{4}$ and carbon nanotubes (CNTs). ${ }^{5}$ In particular, CNT has been suggested as the most promising nanostructure due to its cylindrical structure and high surface-to-volume ratio, which make it ideal for hydrogen storage. However, recent studies $^{5,6}$ indicate that the structure of a pristine CNT is not relevant to satisfy the Department of Energy (DOE) target (6.5 wt \%) at ambient conditions ideal for many practical applications. This is because the pristine CNT has only the $\sim 0.8$ wt $\%$ hydrogen available at ambient conditions. ${ }^{5}$ However, we propose the use of nickel-doped fullerenes as the hydrogen storage media capable of exceeding the DOE target $(6.5 \mathrm{wt} \%)$ at ambient conditions.

The recent experiment ${ }^{6}$ proved that $\mathrm{Ni}$-doped multiwalled (MW) CNTs with outer diameters of $\sim 20 \mathrm{~nm}$ could release 2.8 wt $\% \mathrm{H}_{2}$ at ambient conditions. We found that each $\mathrm{Ni}$ dispersed on the CNT surfaces has the high affinity for hydrogen by storing up to five $\mathrm{H}_{2}$ molecules at ambient conditions. On the other hand, it was also determined that the insertion of $\mathrm{H}_{2}$ into the interlayer of MWCNTs is thermodynamically unstable since it is an endothermic reaction by $24.9 \mathrm{kcal} / \mathrm{mol} \mathrm{H}_{2}$. Consequently, it is considered that $\mathrm{Ni}$ dispersed MWCNTs could release over the 3 wt \% if $\mathrm{Ni}$ nanoparticles could be dispersed on the surfaces of the CNTs grown in vertical shapes with reduced numbers of interlayers. However, the problem is that not all the techniques to control the growth directions and interlayers are available yet. On the other hand, unlike the CNT, a fullerene has al-

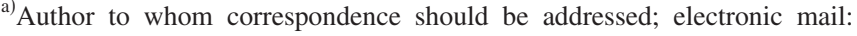
jeungku@kaist.ac.kr ways a single wall and its surface is isotropic; thus there is no need to reduce its interlayer and growth direction. Consequently, the fullerene is considered as a better nanostructure for $\mathrm{Ni}$ dispersion to maximize the hydrogen storage capacity than that for the CNT.

A recent study by Barajas-Barraza et $a l .{ }^{7}$ showed that up to $19 \mathrm{H}_{2}$ molecules could be stored in a $\mathrm{C}_{110}$ fullerene structure. Moreover, Narita et al. ${ }^{8}$ showed through a molecular dynamic simulation study that $\mathrm{H}_{2}$ is stable inside the $\mathrm{C}_{60}$ cage at ambient conditions. On the other hand, they also found that $\mathrm{H}_{2}$ could not escape from the cage due to the high activation barrier of $369.1 \mathrm{kcal} / \mathrm{mol} \mathrm{H}_{2}$ for penetration through the cage; thus, using the inside of the cage as a hydrogen storage site is considered as impractical for many applications. On the other hand, the recent study ${ }^{6}$ showed that $\mathrm{Ni}$ nanoparticles dispersed give the activation barrier of $8.7 \mathrm{kcal} / \mathrm{mol}$ relevant for hydrogen desorption at ambient conditions. In addition, a theoretical study ${ }^{9}$ by Yildirim et al. also found that metals-dispersed nanostructures could be good hydrogen storage materials for practical applications.

To determine electronic wave functions, we use B3LYP (Ref. 10) and KMLYP (Ref. 11) density functional theory (DFT) methods with a split basis set of 6-31 G valence double zeta basis sets ${ }^{12}$ for $\mathrm{Ni}$ and fullerene carbon atoms and $6-31 \mathrm{G}^{* *}$ split valence double zeta basis sets ${ }^{12}$ for hydrogen. The B3LYP is shown to accurately predict geometries and thermochemical data compared to generalized gradient approximation ${ }^{13-17}$ (GGA) and local density approximation (LDA), ${ }^{18,19}$ while the KMLYP has been proven to be more accurate in predicting transition state barriers ${ }^{11}$ than other DFT methods. In addition, here our energies include zero point-energy (ZPE) corrections determined at fully optimized geometry with the same basis sets. We have chosen a $\mathrm{C}_{60}$ molecule with a diameter of $7.12 \AA$ as the specific system for our study, as shown in Fig. 1. The fullerene has the two distinct bond lengths of $1.46 \AA$ for $\mathrm{C}$ - $\mathrm{C}$ bonds and $1.40 \AA$ for $\mathrm{C}=\mathrm{C}$ bonds, which compare to the experimental values of $1.43 \AA$ and $1.39 \AA{ }^{20}$ respectively. 


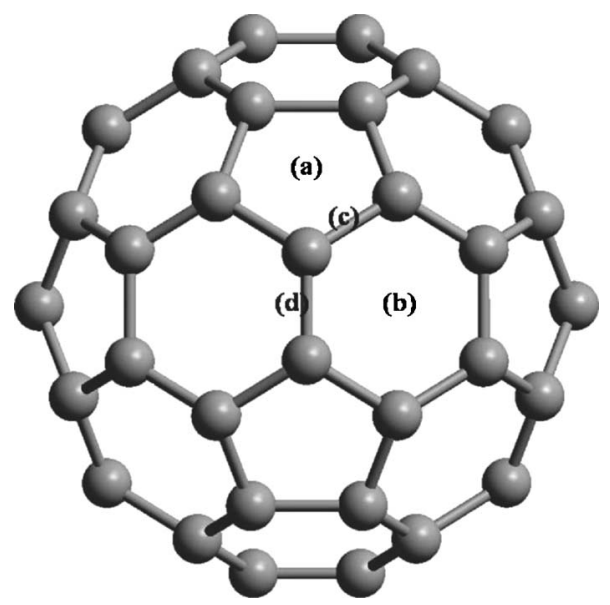

FIG. 1. The optimized geometries for $\mathrm{C}_{60}$. There are four stable positions for $\mathrm{Ni}$ dispersion at: (a) the center of pentagonal ring, (b) the center of hexagonal ring, (c) the edge between pentagonal and hexagonal rings, and (d) the edge between two hexagonal rings, where gray colors are for $\mathrm{C}$ atoms.

First, we have explored the hydrogen storage capacity on the pristine $\mathrm{C}_{60}$. The physical adsorption reaction by a $\mathrm{H}_{2}$ molecule on the outside surface of the fullerene was found to be unstable as it is endothermic by $0.7 \mathrm{kcal} / \mathrm{mol} \mathrm{H}_{2}$, while its corresponding chemical adsorption reaction was determined to have the exothermic enthalpy of $15.2 \mathrm{kcal} / \mathrm{mol} \mathrm{H}_{2}$. However, it was determined that chemical adsorption by $\mathrm{H}_{2}$ molecules on pristine fullerenes has a high activation energy of $83.1 \mathrm{kcal} / \mathrm{mol} \mathrm{H}_{2}$. Consequently, using the computed partition functions for the reactants and the transition state, the reaction rate $k$ of the canonical rate equation ${ }^{21}$ is determined by

$$
k=\Gamma(T) \frac{k_{B} T}{h} \frac{Q_{\mathrm{TS}}}{Q_{A} Q_{B}} \exp \left(\frac{-\Delta E_{0}}{k_{B} T}\right),
$$

where $\Gamma(T)$ is the thermal tunneling coefficient, ${ }^{22} Q_{\mathrm{TS}}$ is the partition functional for the transition state, $Q_{A}$ and $Q_{B}$ are the partition functions for the reactants $A$ and $B$, respectively, and $\Delta E_{0}$ is the barrier height. The resulting dependence of chemisorption on pristine $\mathrm{C}_{60}$ is given by $k=1.76$ $\times 10^{17} \exp (-83.1 \mathrm{kcal} / \mathrm{mol} / R T)(R=2.0 \mathrm{kcal} / \mathrm{mol} \mathrm{K})$. In this respect, chemisorption on a pristine fullerene should occur at a very high temperature instead of at room temperature, which is consistent with the experimental results of Loutfy et $a l^{23}$

Contrary to our previous study on the Ni-dispersed CNTs, ${ }^{6}$ our theoretical calculations find that each $\mathrm{Ni}$ atom dispersed on a fullerene could store up to three $\mathrm{H}_{2}$ molecules at temperatures up to room temperature, where spinpolarization effects were completely considered. Recently, Zhao et al. have also studied hydrogen storage properties on nickel-doped fullerenes. ${ }^{24}$ On the other hand, it was assumed that the metal is the most stable on the center of the pentagonal rings of $\mathrm{C}_{60}$. However, our first-principles calculations prove that the most stable sites for metal dispersion are edge sites between hexagonal rings instead of their assumed center of pentagonal sites. In fact, there are the four distinct sites for $\mathrm{Ni}$ dispersion in $\mathrm{C}_{60}$, as shown in Fig. 1: (a) the center of a pentagonal ring, (b) the center of a hexagonal ring, (c) the edge between hexagonal and pentagonal rings, and (d) the edge between two hexagonal rings. The Gibbs energy of $\Delta G$ for $\mathrm{Ni}$ adsorption is calculated by a following equation:

$$
\Delta G_{\mathrm{Ni} \text { adsorption }}=\Delta H-T \Delta S,
$$

where $\Delta H$ and $\Delta S$ are the enthalpy and entropy changes, respectively. The lowest enthalpy structure is found to be for the case (d), with the case (c) $10.4 \mathrm{kcal} / \mathrm{mol}$, the case (a) $15.7 \mathrm{kcal} / \mathrm{mol}$, and the case (b) $16.6 \mathrm{kcal} / \mathrm{mol}$ higher. Consequently, this indicates that the case (d) corresponds to the global minimum state. On the other hand, the largest diffusion barrier of $\mathrm{Ni}$ diffusion from the local minima in the above to the global minimum state (d) is determined to be very small $(6.3 \mathrm{kcal} / \mathrm{mol})$, thus implying that $\mathrm{Ni}$ in the local minimum states could easily transform to the global minimum state even at the very low temperatures larger than 109 $\mathrm{K}$. In addition, the entropy difference of $0.03 \mathrm{kcal} / \mathrm{mol} \mathrm{K}$ between the global minimum (d) and the dissociated state into a fullerene plus $\mathrm{Ni}$ atoms finds that the global minimum state for a Ni-dispersed fullerene could be stable up to 1176 $\mathrm{K}$. The exothermic adsorption energy for $\mathrm{Ni}$ at the most stable position of (d) is $37.6 \mathrm{kcal} / \mathrm{mol}$, and the distances be-

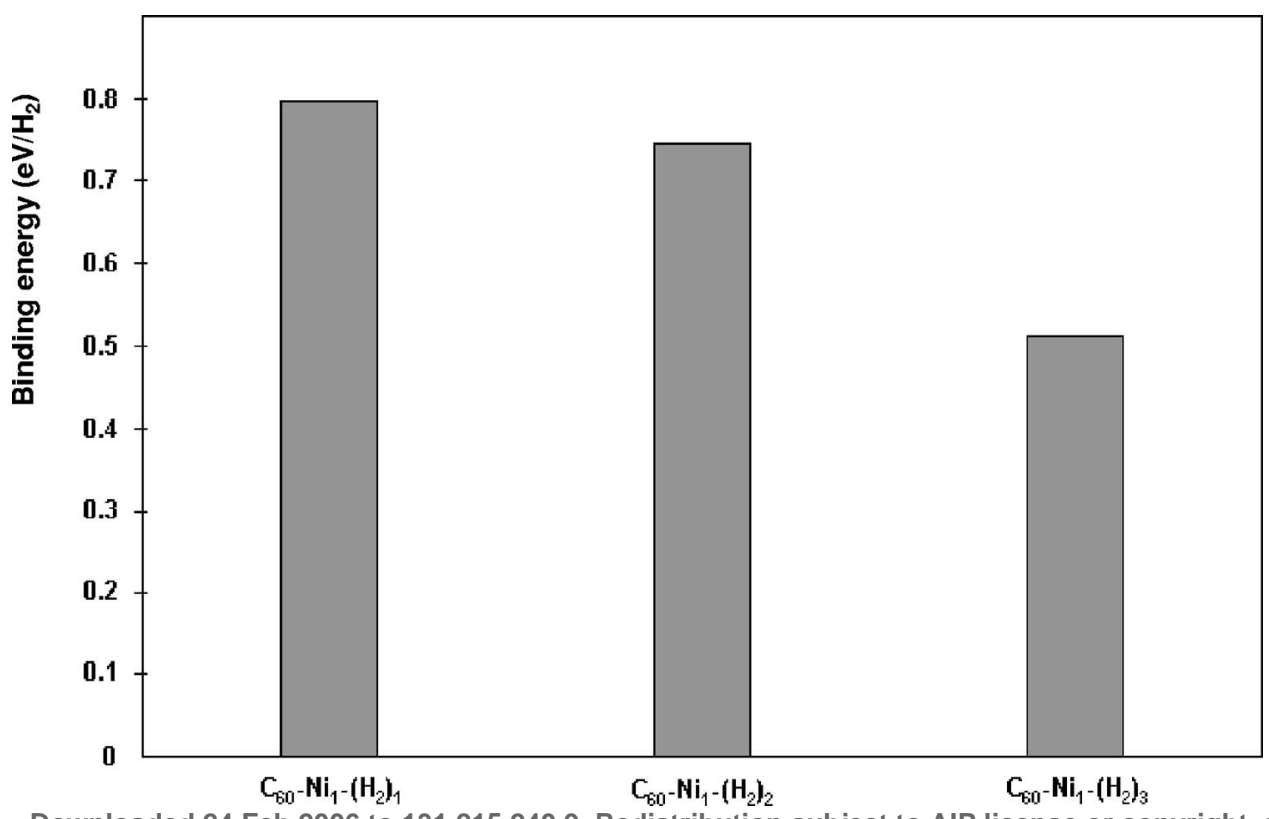

FIG. 2. Hydrogen adsorption energy per $\mathrm{H}_{2}$ on the $\mathrm{C}_{60}-\mathrm{Ni}_{1}-\left(\mathrm{H}_{2}\right)_{n}$ cluster, where $n$ is 1 to 3 . 


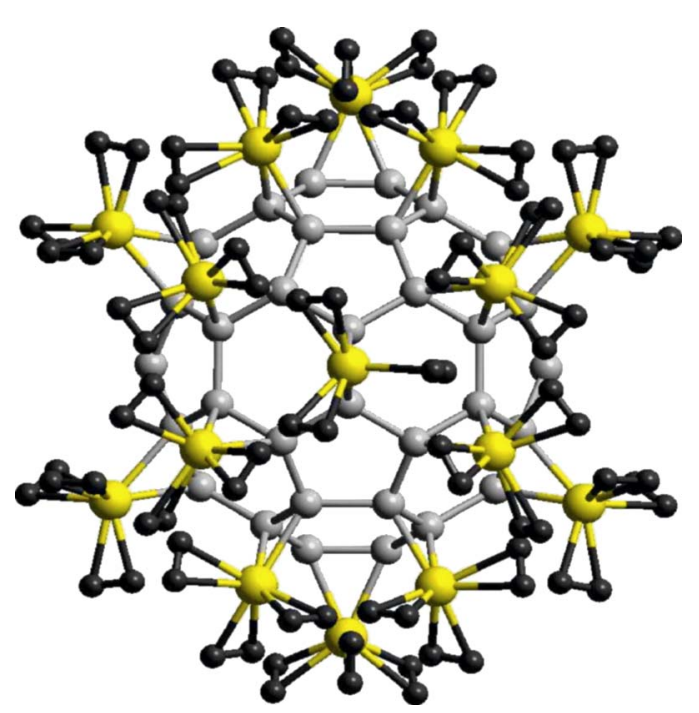

FIG. 3. (Color online) Hydrogenated Ni-dispersed $\mathrm{C}_{60}$. Three hydrogen molecules could be adsorbed to a $\mathrm{Ni}$ atom. Carbon, nickel, and hydrogen atoms are shown in silver, yellow, and black, respectively.

tween $\mathrm{Ni}$ atoms and their nearest $\mathrm{C}$ atom are $1.82 \AA$. $\mathrm{A} \mathrm{C}_{60}$ includes two different $\mathrm{C}-\mathrm{C}$ and $\mathrm{C}=\mathrm{C}$ bond characters. $\mathrm{A}$ $\mathrm{C}=\mathrm{C}$ bond site in the edge between two hexagonal ring sites is found to be more favorable for metal dispersion.

In addition, we find that the Mulliken charge on $\mathrm{Ni}$ is 0.51 . Consequently, the resulting dipole moment of 5.15 D from a Ni- $\mathrm{C}_{60}$ cluster, compared to the case of $0.002 \mathrm{D}$ for the pristine $\mathrm{C}_{60}$, is sufficient to enhance the van der Waal's interaction between hydrogen and $\mathrm{Ni}-\mathrm{C}_{60}$. We also determine the $\mathrm{Ni}$ adsorption energies of $-47.5 \mathrm{kcal} / \mathrm{mol} \mathrm{Ni}$ and $-54.5 \mathrm{kcal} / \mathrm{mol} \mathrm{Ni}$ for $\mathrm{Ni}_{2}$ and $\mathrm{Ni}_{3}$ nanoparticles, respectively. All Ni atoms in these cases were also found to be most stable at the edges of the same hexagonal ring sites, as in the case of the first Ni. The $\mathrm{C}-\mathrm{Ni}$ and $\mathrm{Ni}-\mathrm{Ni}$ bond distances for $\mathrm{C}_{60}-\mathrm{Ni}_{2}$ are determined to be 1.82 and $2.52 \AA$, while the $\mathrm{C}-\mathrm{Ni}$ bond and $\mathrm{Ni}-\mathrm{Ni}$ bond distances for $\mathrm{C}_{60}-\mathrm{Ni}_{3}$ are 1.88 and $2.53 \AA$, respectively.

Figure 2 shows the hydrogen adsorption behaviors as hydrogen molecules adsorbed in the $\mathrm{C}_{60}-\mathrm{Ni}_{1}$ cluster increase. The physisorption energy is calculated by a following equation:

$$
\Delta H_{\text {physi }}=H_{\text {tot }}\left(\mathrm{H}_{2}+\text { fullerene }\right)-H_{\text {tot }}(\text { fullerene })-H_{\text {tot }}\left(\mathrm{H}_{2}\right)
$$

where $H_{\text {tot }}\left(\mathrm{H}_{2}+\right.$ fullerene $)$ is the enthalpy of the fullerene- $\mathrm{H}_{2}$ system at $298 \mathrm{~K}, H_{\text {tot }}$ (fullerene) is the enthalpy for the fullerene, and $H_{\text {tot }}\left(\mathrm{H}_{2}\right)$ is the enthalpy for an optimized $\mathrm{H}_{2}$ molecule. The binding enthalpy change of the first hydrogen molecule adsorbed by the nickel atom is determined to be $18.5 \mathrm{kcal} / \mathrm{mol}$, which is lower than the result of Zhao et al. ${ }^{24}$ by $31.8 \mathrm{kcal} / \mathrm{mol}$. Zhao et al. have reported that $\mathrm{Ni}$ could store only one hydrogen molecule. However, our calculations show that $\mathrm{Ni}$ is more likely to store up to three hydrogen molecules rather than only one. This discrepancy appears to be reasonable. Zhao et al. assumed that $\mathrm{Ni}$ is the most stable at the center of a pentagonal ring in the fullerene, while our results show the edge between two hexagonal rings for the most stable site of the Ni atom, as mentioned above. Moreover, we find that three hydrogen molecules could be adsorbed around each $\mathrm{Ni}$ with its exothermic enthalpy of
$11.8 \mathrm{kcal} / \mathrm{mol} \mathrm{H}_{2}$. It should be noted that this $\mathrm{H}_{2}$-dispersed fullerene is in a global minimum state. The bond distance between hydrogen and $\mathrm{Ni}$ atoms ranges from 1.62 to $1.73 \AA$, while $\mathrm{H}-\mathrm{H}$ bonds slightly elongate with bond distances ranging from 0.79 to $0.81 \AA$ compared to the original $\mathrm{H}-\mathrm{H}$ bond distance of $0.73 \AA$, which indicates that the bonds between hydrogen and $\mathrm{Ni}$ have both physical and chemical bond characters. In $\mathrm{C}_{60}-\mathrm{Ni}_{1}$, the dipole moment is calculated to be $4.40 \mathrm{D}$. In the case of $\mathrm{C}_{60}-\mathrm{Ni}_{2}$, it is also determined that three hydrogen molecules could be adsorbed around each $\mathrm{Ni}$ atom. The adsorption energy for this case is determined to be $-9.7 \mathrm{kcal} / \mathrm{mol} \mathrm{H}_{2}$, and the bond lengths between hydrogen and $\mathrm{Ni}$ atoms range from 1.61 to $1.76 \AA$. In the $\mathrm{C}_{60}-\mathrm{Ni}_{3}$ cluster, each $\mathrm{Ni}$ atom also stores three hydrogen molecules with the enthalpy change of $-7.6 \mathrm{kcal} / \mathrm{mol} \mathrm{H}_{2}$ and the bond distances ranging from 1.60 to $1.77 \AA$. Consequently, these results indicate that the $\mathrm{Ni}$-dispersed $\mathrm{C}_{60}$ could store 90 hydrogen molecules attached to $30 \mathrm{Ni}$ atoms, as shown in Fig. 3 . Thus, this results in the hydrogen storage capacity is up to 6.8 wt $\%$.

In conclusion, it was found that each $\mathrm{Ni}$ atom adsorbed three hydrogen molecules. These results indicate that a Nidispersed fullerene could have $6.8 \mathrm{wt} \%$ for its hydrogen storage capacity, which exceeds the DOE target. This enhanced hydrogen storage capacity is attributed to the fact that three $\mathrm{H}_{2}$ could be adsorbed around each polarized $\mathrm{Ni}$ involving the charge transfer from fullerenes.

The computational resources at the KAIST have been supported by KOSEF (Grant No. R012005000103330) and by the KRF (Grant No. 2005-005-J09703).

${ }^{1}$ L. Schlapbach and A. Züttel, Nature (London) 414, 353 (2001).

${ }^{2}$ N. Takeichi, H. Senoh, T. Yokota, H. Tsuruta, K. Hamada, H. T. Takeshita, H. Tanaka, T. Kiyobayashi, T. Takano, and N. Kuriyama, Int. J. Hydrogen Energy 28, 1121 (2003).

${ }^{3}$ S. M. Aceves, J. Martinez-Frias, and O. Garcia-Villazana, Int. J. Hydrogen Energy 25, 1075 (2000).

${ }^{4}$ G. Sandrock and G. Thomas, Appl. Phys. A 72, 153 (2001).

${ }^{5}$ Q. Wang and J. K. Johnson, J. Chem. Phys. 110, 577 (1999).

${ }^{6}$ H. S. Kim, H. Lee, K. S. Han, J. H. Kim, M. S. Song, M. S. Park, J. Y. Lee, and J. K. Kang, J. Phys. Chem. B 109, 8983 (2005).

${ }^{7}$ R. E. Barajas-Barraza and R. A. Guirado, Phys. Rev. B 66, 155426 (2002).

${ }^{8}$ I. Narita and T. Oku, Diamond Relat. Mater. 11, 945 (2002).

${ }^{9}$ T. Yildirim and S. Ciraci, Phys. Rev. Lett. 94, 175501 (2005).

${ }^{10}$ A. D. Becke, J. Chem. Phys. 98, 5648 (1993).

${ }^{11}$ J. K. Kang and C. B. Musgrave, J. Chem. Phys. 115, 11040 (2001).

${ }^{12}$ A. D. McLean and G. S. Chandler, J. Chem. Phys. 72, 5639 (1980); R. Ditchfield, W. J. Hehre, and J. A. Pople, ibid. 54, 724 (1971); M. J. Frisch,

J. A. Pople, and J. S. Binkley, ibid. 80, 3265 (1984).

${ }^{13}$ A. D. Becke, J. Chem. Phys. 85, 7184 (1986).

${ }^{14}$ J. P. Perdew, Phys. Rev. B 33, 8822 (1986).

${ }^{15}$ A. D. Becke, Phys. Rev. A 38, 3098 (1988).

${ }^{16}$ P. M. W. Gill, Mol. Phys. 89, 433 (1996).

${ }^{17}$ J. P. Perdew, K. Burke, and M. Ernzerhof, Phys. Rev. Lett. 77, 3865 (1996).

${ }^{18}$ J. C. Slater, Quantum Theory of Molecular and Solids: The Self-Consistent Field for Molecular and Solids (McGraw-Hill, New York, 1974), Vol. 4.

${ }^{19}$ S. H. Vosko, L. Wilk, and M. Nusair, Can. J. Phys. 58, 1200 (1980).

${ }^{20}$ J. M. Hawkins, Acc. Chem. Res. 25, 150 (1992).

${ }^{21}$ K. J. Laidler, Chemical Kinetics (McGraw-Hill, New York, 1950), Chap. 3.

${ }^{22}$ J. K. Kang and C. B. Musgrave, J. Chem. Phys. 115, 11040 (2001).

${ }^{23}$ R. O. Loutfy and E. M. Wexler, IEA Task 12 report, 2001 (unpublished), http://www.ieahia.org/pdfs/NN0094u.pdf.

${ }^{24}$ Y. Zhao, Y. H. Kim, A. C. Dillon, M. J. Heben, and S. B. Zhang, Phys. Rev. Lett. 94, 155504 (2005). 